\title{
Syekh H. Mukhtar Abdul Karim Ambai Dan Pembaharuan Dakwah Di Kerinci
}

\author{
Ahmad Zuhdi \\ Institut Agama Islam Negeri (IAIN) Kerinci \\ Zuhdi69@siswa.um.edu.my
}

\begin{abstract}
This article aims to review and describe the da'wah figure of Sheikh H. Mukhtar Abdul Karim Ambai as a charismatic cleric in the renewal of Islamic da'wah in Kerinci. This article wants to see what methods are packaged and implemented in their da'wah activities. This title is deliberately presented to remember the services and struggles that have been carried out throughout his life. He preached and educated people to return to practice the teachings of Islam as stated in the Qur'an and the hadith of the Prophet Mubammad. Although there were not a few obstacles and challenges of da'wah that were felt at that time, Sheikh Mukhtar never felt tired. Even in the atmosphere, the Dutch colonial and colonial times were still engulfed. His da'wah strategy is quite easy to accept and practice by the people of Kerinci and its surroundings.
\end{abstract}

Keywords; Sheikh H. Mukhtar, Ulama, Reform and Da'wah

\begin{abstract}
Abstrak
Artikel ini bertujuan untuk mengulas dan mendeskripsikan tokoh dakwah Syekh H. Mukhtar Abdul Karim Ambai sebagai ulama karismatik dalam pembaharuan dakwah Islam di Kerinci. Artikel ini ingin melihat metode apa yang dikemas dan diimplemetasikan dalam kegiatan dakwahnya. Judul ini sengaja diketengahkan untuk mengingat kembali jasa dan perjuangan yang telah dilakukan sepanjang hidupnya. Beliau berdakwah dan mendidik masyarakat agar kembali mengamalkan ajaran Islam sebagaimana yang telah dihariskan dalam al-Quran dan hadis Rasulullah SAW. Meskipun tidak sedikit hambatan dan tantangan dakwah yang dirasakan ketika itu, namun Syekh Mukhtar tidak pernah merasa lelah. Bahkan dalam suasana masih saja diliputi masa kolonial dan penjajahan Belanda. Strategi dakwahnya cukup mudah diterima dan diamalkan oleh masyarakat Kerinci dan sekitarnya.
\end{abstract}

Kata kunci; Syekh H. Mukhtar, Ulama, Pembaharuan dan Dakwah

\section{Pendahuluan}

Dinamika dakwah ialah sebuah adu kekuatan antara pembaharuan konservatif dan pembaharuan progresif untuk masa depan. Hal ini merupakan agenda laten umat Islam sepanjang sejarah. Gerakan pembaharuan dalam Islam biasa disebut tajdid yang memiliki dasar kuat pada warisan pengalaman sejarah kaum muslimin. ${ }^{1}$ Di mana hal ini tercatat dalam sejarah bahwa masa kejayaan Islam

1 Akhirudin, "dakwah dan pembaharuan pemahaman islam," kordinat xvii, no. 2 
pernah terjadi pembaharuan pemikiran dari pola tradisional-konserfatid ke pola rasional-modern. ${ }^{2}$ Sehingga, perlu disimpulkan bahwa gerakan pembaharuan berkembang jauh sebelum berkembangny aliran-aliran dalam Islam. ${ }^{3}$

Pembaharuan dalam perspektif Islam merupakan sesuatu yang berkaitan dengan Islamyang sebelumnya tidak ada dengan melakukan pemurnian. Pemurnian dalma kontkes ini ialah dimana usaha untuk mengambalikan keadaan seperti semula. ${ }^{4}$ Masyarakat Barat menyebutkan bahawa pembaharuan merupakan pikiran, aliran, gerakan dan usaha untuk mengubah adat istiadat, intiusi lama untuk disesuaikan dengan perkembangan zaman dan faham yang ada. ${ }^{5}$ Agar tidak ada pertentangan antara norma-norma dan ajaran Islam dengan semangat zaman. ${ }^{6}$

Adapun beberapa yang melatarbelakangi timbulnya pembaharuan dakwah Islam, diantaranya ${ }^{7}$ : Pertama, paham tauhid yang dianut kaum muslimin telah tercampur dengan kebiasaan tarekat atau pemujaan lainnya. Kedua, sifat jumud ummat Islam dalam berhenti berfikir dan berusaha. Ketiga, ummat Islam selalu terpecah belah. Keempat, pengaruh barat. Di samping itu, pembaharuan dilakukan sebagai upaya prinsip-prinsip dan ajaran-ajaran Islam kepada pemeluknya.

Menyadari hal tersebut, tokoh dakwah Syekh H. Mukhtar Abdul Karim Ambai tampil dengan menyerukan umat Islam agar menyadari jati dirinya sebagai umat yang pernah jaya di muka bumi, dengan gerakan pembaharuan yang dilakukan Syekh H.Mukhtar di tanah Kerinci. Pada kontkes ini, Syekh H. Mukhtar berupaya menegakkan prinsip nya untuk mengajak umat muslim bangkit dari tidur lelapnya agar bisa keluar dari masa jahiliyah. Di mana, sebelum H Mukhtar menjadi seorang ulama, da'I dan intelektual, beliau telah memperkayakan dirinya dengan pelbagai ilmu penegetahuan sehingggalah kehediran beliau di tengah-tengah masayarakat memang sangaat diharapkan. Apalagi keteika itu keadaan masyarakat masih dipengaruhi oleh amalan-amalan jahiliyah seperti memuja roh, pokok kayu yang dianggap boleh memberikan pertolongan dan sebagaainya. Disaat-saat seperti inilah H. Mukhtar muncul untuk menghimpun serta menjalin perpaduan sesama mereka.

(2018): 400 .

${ }^{2}$ H.L. Beek and N.J.G Kaptien, Pandangan Barat Terhadap Literatun Hukum, Filosofot, Teologi Dan Mistik Tradisi Islam (Jakarta: INIS, 1998), 55.

3 P.S.J. Van Koningsvela, Naskah-Naskah Yunani Tentang Bait Al-Hikmah Dan Kebijakan Khalifah Al-Ma'mun Dalam Herman Leonard Beek Dan Niro Kaptien (Red) Studi Belanda Kontemporer Tetang Islam (Jakarta: INIS, 1993), 49-50.

${ }^{4}$ Bustami Mubammad Sa'Id, Gerakan Pmebaharuan Antara Agama MOdernisme Dan Tajdiduddin (Bekasi: WacanaLazuardi, 1995), 29.

${ }^{5}$ Harun Nasution, Pembaharuan Dalam Islam Syarah Pemikiran Dan Gerakan (cet-8, 1991), 11.

6 Rifyal Ka'bah, "Modernisme Dan Fundamentalisme Ditinjau Dari Konteks Islam," Jurnal Ilmu Dan Kebudayaan Ulumul Qur'an 3, no. VI (1998): 29

7 Yusran Asmuni, Pengantar Studi Pemikiran Dan Gerakan Pembaharuan Dalam Dunia Islam, Cet-2 (Jakarta: Raja Grafindo Persada, 1998), 7 


\section{Metode Penelitian}

Kajian ini menggunakan metode pendekatan kualitatif adapun jenis penelitiannya bersifat historis. Jenis penelitian ini merupakan metode pengumpulan data bersifat deskriptif yang dikumpulkan berdasarkan data-data yang terjadi pada masa lalu atau lampau. ${ }^{8}$ Metode ini penulis anggap sangat relevan untuk melihat pembaharuan yang dilakukan oleh Syekh H. Mukhtar bin Abdul Karim semasa hidupnya. Di mana penelitian ini di dasarkan pada empat tahap yaitu heuristic (pengumpulan data sejarah), pengujian terhadap validitas data, interpretasi data dan menarik kesimpulan. Tahapan ini disebut sebagai historiografi sehingga tidak asal menarik sebuah kesimpulan semata. ${ }^{9}$

\section{Hasil Dan Pembahasan}

\section{Biografi Syekh H. Mukhtar bin Abdul Karim}

Syekh H. Mukhtar bin Abdul Karim merupakan seorang da'I dan juga pemikir Islam semasa di Kerinci. Beliau terekenal dengan sikap keterbukaannya di samping tuliasan dan karyanya. Beliau dilahirkan di Desa Ambai Kabupaten Kerinci pada 25 September 1902 dari keluarga petani. Ayah beliau bernama H Abdul Karim dan ibu beliau bernama Siti Saltut. Beliau adalah anak keempat dari empat bersaudara dan dididik dalam keluarga yang taat beragama dengan ilmu fardu ain dan adab-adab Islam, sebeliaum beliau mendapat pendidikan di sekolah. Beliau telah banyak menimba ilmu dari kedua orang tuanya, terutama ilmu-ilmu agama, pendidikan Quran, Tajwid, membaca dan menulis. Kecerdiakan dan kecerdasan H. Mukhtar diadapati menonjol sejak kecil lagi. H. Mukhtar yang lebih awal mendapat pendidikan dari kedua oaring tuannya, terutama pendidikan agama sebagai ilmu asas yang dikuasai oleh H. Mukhtar sejak dari kecil lagi, mendorong beliau mencapai cita-cita untuk menuntut ditanah Arab.

Pada tahun 1925 H. Mukhtar berangkat ke tanah suci Makkah alMukarrahmah dan menetap di sana selama 12 tahun. Sewaktu menuntut di tanah Arab, H. Mukhtar telah menguasai beberapa disiplin ilmu keIslaman, bahasa Arab, Tafsir dan hukum-hukum. Ketika belajar di Mekkah, beliau berkesempatan melawat Syiria. Bait al-Maqdis, Mesir dan Pakistan. Selepas belajar di Mekkah selama 16 tahun, Sekembalinya dari Mekkah, beliau tidak langsung pulang ke Kerinci tetpai singgah dahulu di Hulu Klang, Selanggor, karena disini ramai sanak saudaranya yang sudah menjadi penduduk tetap Malaysia. Di sisnilah beliau mengembangkan ilmunya, dan mendidikan satu madrasah atas permintaan penduduk Hulu Klang. Madrasah itu diberi nama Madrasah Falahiyah dan muridnya mencapai 500 orang. Kemudiannya beliau kembali ke tanah air bekerja dan berkhidmat sesuai dengan bidang dan pengetahuan serta pengalaman sebagai seorang guru da'I dan Mubaligh.

Pada tahun 1942 H Mukhtar dipanggil pulang oleh kaum keluarganya di

${ }^{8}$ Sugiyono, Metode Penelitian Kuantitatif, Kualitatif Dan R\&D, Cet ke-26 (Bandung: Alfabeta, 2017).

${ }^{9}$ H Sjamsudin, Metodologi Sejarah (Yogyakarta: Ombak, 2012). 
Kerinci yang sudah rindu ingin bertemu. Setelah berada di Kerinci beliau melihat masyarakat masih ramai yang belum mengamalkan ajaran Islam, bahkan masih ada di antara penduduk yang percaya dengan tahayul dan animisme. Meliahat keadaan seperti ini, beliaupun memulai kerjanya menyeru masyarakat kejalan yang benar, iaitu dengan dakwah Islamiah dengan membentuk kelompok pengaiian yang berpusat dirumah besar beliau yang terletak berhampiran dengan lebuh raya Kerinci- Jambi.

Jumalah pengikutnya kian hari kian bertambah dan mendapat kemajuan dengan pesatnya. Tapi zaman penjajahan jepang pengajian ini mengalami sedikit kemunduran hingga tahun 1945. Belum lagi Indonesia memperolehi Kemerdekaan dari tangan penjajahan, $\mathrm{H}$ Mukhtar berusaha mempersatukan masyarakat dalam satu organisasi iaitu Jamiatul Ikhsaniah pada tanggal 1 Januari 1945. Organisasi lahir dari satu kampong yang kecil kemudian boleh tersebar diseluruh Kerinci.

Dua tahun kemudian, yaitu tahun 1947 beliau membentuk komondo jihad di beri nama "Jamiatul Ikhsaniah" yang mayoriti ialah kaum pemuda. Ketika itu penjajah Belanda masih berkeingginan menguasai Indonesia termasuk daerah Kerinci. Kelahiran Jamiatul Ikhsaniyah bertujuan menentang penjajah Belanda. Pada tahun 1947 pengikut H, mukhtar bertambah banyak, baik dari kalangan tua mahupun generasi muda, kemudian beliau mengharapkan agar anak-anak juga ikut dalam pengajian yang didirikan.

Perkembangan dakwah yang semakin pesat dan nama $H$. Mukhtar tersebar merata di Kerinci, Padang dan Jambi. Beliau di sanjungi oleh pemerintah, seperti gubernur yang pertama iaitu Djamin datuk Bagindo 1956-1957, kemudain Muhammad Yusuf Singedekane,

H. A. Manaf, R. M. Noer Atmadibrata, Djamaludin Tambunan, H. Eddy Sabhar hinggalah Masjhun Sofwan 1979.10 (ilyas 1997) Adanya perhubungan H. Mukhtar dengan pembesar kerajaan, dimana beliau telah diberi kepercayaan oleh pemerintah dalam merancang dan melaksanakan perkembangan dakwah Islamiah di Kerinci khususnya dan provinsi Jambi umumnya.

Perwatakan zahir H. Mukhtar jelas sebagai seorang yang sederhana hidupnya, malah sampai ketingkat zuhud. Hal ini terlihat pada peri kehidupan beliau, pakaian, makanan dan lainnya. Beliau lebih suka mengurus kehidupan hariannya secara bersendiri. Beliau pergi sendiri ke pasar untuk membeli barang-barang keperluan dapur dan kadang-kadang masak sendiri. Beliau seorang manusian berperasaan halus dan bertimbang rasa, tidak menyakiti dan menyusahkan orang lain. Pada 5 Oktober 1977, dalam usia 75 tahun, beliau telah kembali kerahmatullah di Rumah Sakit umum Padang (RSUP). Jenazah di sembahyangkan oleh ribuan orang dan kematiannya mendapat perhatian media cetak Jambi antaranya surat kabar AMPERA serta media lain seperti RRI jambi, membuat liputan diatas kehilangan seorang ulama dan da'I itu. Beliau dimakamkan sebelah Pesantren Jamiatul Ikhsaniyah Mukhtaariyah Ambai.

${ }^{10}$ Ilyas Ismail A, Filsafat Dakwah, Rekayasa Membangun Agama Dan Peradaban Islam (Jakarta: Kencana, 2011). 


\section{Dakwah Syekh H. Mukhtar bin Abdul Karim Sebagai Ulama Karismatik}

Dakwah merupakan salah satu titik pusat dalam perluasan agama, karena agama sangat bergantung pada gerak dinamis dari aktivitas dakwah yang berjalan terus menerus tanpa akhir. Tanpa kegiatan dakwah, agama akan mengalami kemunduran serta kelumpuhan dalam perkembangannya. ${ }^{11}$ Itulah sebabnya, dakwah mempunyai peran penting dalam syiar dan penyebaran agama Islam. Dakwah penyebaran Islam menggunakan prinsip rahmatan lile alamin dengan menjunjung tinggi nilai akhlak, tidak melalui kekerasan, pemaksaan atau kekuatan senjata. Dakwah memiliki tujuan utama untuk mengubah tingkah laku manusia dari tingkah laku negatif ke tingkah laku positif. ${ }^{12}$ Menjalankan dakwah merupakan suatu tuntutan dalam Islam. H. Mukhtar Abdul Karim berusaha membuka langkah memenuhi tuntutan Islam tersebut dengan melakukan kegiatan dakwah baik di dalam negeri maupun di luar negeri.

Jika sebelumnya, H. Mukhtar Abdul Karim selepas belajar di Mekkah selama 16 tahun, berkesempatan menjalankan misi dakwahnya di luar Kerinci yaitu di Hulu Klang, Selanggor, karena disini ramai sanak saudaranya yang sudah menjadi penduduk tetap Malaysia. H. Mukhtar Abdul Karim berusaha membuka langkah memenuhi tuntutan Islam terutama di negerinya sendiri secara umum dalam provinsi Jambi dan khasnya di Kerinci. Perjuangan dakwah yang dapat dilakukan dapat dilihat dalam beberapa ospek antaranya di bidang keagamaan, bidang politik dan pendidikan. H. Mukhtar berdakwah di Kerinci kepada semua golongan dan peringkat masyarakat dari kalangan awam sampai ketahap pemimpin atau pemerintah. Untuk menarik perhatian di kalangan pelbagai kelompok dan golongan supaya mereka mengenali Islam. H. Mukhtar mengunakan pelbagai pendekatan yang sesuai dengan psikologi kelompok masyarakat. H. Mukhtar menyampaikan dakwah Islamiah dengan mengemukan alasan-alasan yang mudah difahami serta pendekatan yang mudah diterima. ${ }^{13}$

Kehadiran beliau amat disenangi, dihormati dan dimuliakan karena keramahan, kejujuran serta pergorbanannya kepada masyarakat. Walaupun $\mathrm{H}$. Mukhtar juga pernah dianggap seorang ulama dan da'I tardisioanal yang ekstrim, tapi hal tersebut dilontarkan oleh oaring-orang yang sengaja untuk melemah dan mematahkan semangat beliau. Beliau seorang yang tegas dalam masalah akidah lebih-lebih lagi apabila meliahat keadaan masyarakat Kerinci pada ketika itu masih ada yang mempercayai tahayul dan kekuatan alam lainnya seperti memuja pokok, angin, matahari, api dan sebagainya sebagai tempat meminta pertolonngan dan perlindungan. Kepercayaan ini telah dibersihkan secara berperingkat- peringkat

11 Indriany Aisyah Saleh, Chatib Saefullah, and Tata Sukayat, "Problematika Dakwah Penyuluh Agama," Tabligh Jurnal Komunikasi Dan Penyiaran Islam 5, no. 3 (2020): 287-308.

12 Abdul Choliq, "Dakwah Melalui Media Sosial Facebook," Jurnal Dakwah Tabligh Vol.16, no. 2 (2018): 170.

${ }_{13}$ Budhi Vrihaspati Jauhari and Dkk, Tinjauan Sejarah Kebudayaan Islam Di Alam Kerinci (Sungai Penuh: Bina Potensia, 2014). 
menuju jalan Islam iaitu menyembah Allah SWT. Ia merupakan matlamat dari kegiatan dakwah Islamiah, sehingga ajaran Islam yang disampaikan dapat diamalkan dalam hidup dan kehidupan, baik sebagai petani, pedagaang mahupun pemimpin pemerintah.

H. Mukhtar tidak mau kepercayaan masyarakat berubah disebabkan oleh kedudukan yang nisbi, yang hanya memperolehi kesenangan sementara, berbanding jawatan yang di berikan masyarakat dan umat iaitu "Tuan Guru dan "Syekh" yang tidak ternilai dan mempunyai tanggung jawab yang besar, selain kepada manusia juga kepada Allah SWTT. Dissinilah letak kunci keberhasilan dakwah H. Mukhtar di Kerinci, iaitu berdakwah dengan ketulusan dan keikhlasan. Keakraban H. Mukhtar dengan masyarakat menjadikannya orang yang paling diharapan di Kerinci, Jambi dan sekitar Sumatera Barat iaitu Padang Panjang dan Bukit Tinggi.

\section{Matlamat dan Halangan Dakwah Syekh H. Mukhtar Abdul Karim}

Syekh H. Mukhtar telah mengunakan satu pendekatan menyeru manusia kepada satu keyakinan atau iman dan kepercayaan dengan mengelakan dari berlakunya paksaan, kekerasan atau ancaman. Beliau memberi keterangan dan hujjah yang boleh difahami dan diterima oleh masyarakat. Beliau telah menyaksikan sendiri keadaan masyarakat ketika itu yang sangat memerlukan bimbingan dan perhatian yang serius. Usaha untuk membentuk masyarakat dan kepribadian manusia tidak semudah apa yang dijangkakan. Oleh itu, H. mukhtar berusaha melaksanakan dakwah Islamiahnya dengan segala kemampuan dan kesanggupan yang ada pada dirinya dengan melintasi segala bentuk halangan dan cabaran untuk memastikan masyarakat atau sasaran dakwahnya dapat menerima, seterusnya kembali kepangkal jalan Islam dengan meninggalkan segala kesyirikan dan kekhurafatan.

\section{a) Potret Dakwah H. Mukhtar}

Sejarah perkembangan agama tauhid menunjukan bahawa kebenaran yang diturunkan Allah terus menerus dapat berkembang dengan baik, disebar luaskan melalui dakwah oleh para Nabi, Rasul, Ulama dan Mubaligh. Allah SW'T tidaklah memerintahkan sesuatu kebaikan melainkan ada pula disediakan atau keuntunngan sebagai ganjarannya. Hal ini tidak syak lagi bagi orang yang beriman. Mereka berdakwah bukan karena mencari kesenangan duniawi atau popularity, tetapi untuk mencari keredhaan Allah adalah kunci kebahagiaan yang abadi dan sejati. Oleh itu dakwah adalah usaha atau kegiatan yang bermatlamat. Matlamat dakwah Islam adalah mengubah pandangan hidup seseorang. Dari perubahan pandangan hidup ini akan berybah pula pola piker dan pola sikap menjadi Islami. Demikian pula halnya denngan $\mathrm{H}$. Mukhtar yang mempunyai matlamat dakwah iaitu menyeru masyarakat kepada kebenaran, merubah ajaran animism dan dinamisme kepada ajaran Islam serta penghayatn Islam dalam bentuk amalan Harian. 
1) Menyeru Masyarakat Kepada Kebenaran

Diantara karunia Allah SW'T yang terbesar kepada H. Mukhtar Abdul Karim ialah keupayaan beliau mengembalikan masyarakat Kerinci kepada kefahaman yang betul seperti yang dituntut oleh Islam, jauh dari kesalahan, bersih dalam syariah iaitu Islam yang benar-benar murni dari sumbernya yang asli, Kitab Allah dan Sunnah Nabi-Nya Muhammad saw. Kondisi masyarakat Kerinci yang masih banyak kekurangan dalam amalan harian yang masih bercampur aduk dengan adat dan bid'ah seperti kenduri adat, upacara tolak bala dan sebagainya yang didalamnya terdapat unsur-unsur yang bertentangan dengan Islam. Meskipun demikian, H. Mukhtar tetap meneruskan usaha dengan kegiatan dakwah Islamiah. Walaupun adanya pertentangan antara kebenaran yang diserunya dengan kebathilan yang ada di tengah-tengah masyarakat Kerinci.

Beliau terus gigih dan menghadapinya dengan penuh ketakwaan kepada Allah. Dalam satu pengajian, H. mukhtar menyampaikan kepada murid-muridnya bahawa kebenaran dapat berdiri dengan sendirinya, tetapi ia akan tegak dengan usaha umat Islam dan juga pada pembesar yang memiliki keutamaan tertentu (Abu Bakar Arsyad 1997). Dalam usaha menegakkan dakwah Islamiah, H. Mukhtar adalah tetap berpegang teguh pada kebenaran Ilahi, menunjukan keberanian dan sanggup menanggung resiko sesuai dengan batas kemampuan.

Dalam dakwah nya $H$. Muhktar kerap mengadakan pengajian dengan menjunjung nilai-nilai kebenaran mulai dari perkataan atau ucapan, niat, janji dan amal. Selain itu, beliau juga senantiasa terus mengedukasi masyarakat Kerinci agar dapat mengamalkan ajaran Islam dengan baik, dan meninggalkan amalan-amalan yang tidak sesuai ataupu tidak diajarkan dalam agama Islam seperti syirik, munafik dan sebagainya. H. Mukhtar dengan berhati-hati dan penuh kesungguhan menyedarkan masyarakat, untuk berbuat benar dengan tidak memaksa tetapi menyeru dengan penuh kebijaksanaan. Adapun langkah penerapan kebenaran yang diberikan oleh H. Mukhtar ialah berdasarkan wahyu Allah yakni Al-Quran.

H. Mukhtar sentiasa mengingatkan manusia supaya harus memerhatikan peraturan-peraturan (Ayatullah) yang berlaku pada diri manusia dan seluruh alam. Dengan selalu mengunakan pendekatan soal jawab mengenai apa yang berlaku pada kehidupan seharian manusia. Ia berlegar sekitar hubungan Pencipta dangan yang dicipta. Umpamnaya siapakah yang mencipta alam ini? Siapakah yang menumbuhkan tanaman sehingga manusia dan hewan dapat mengambil faedah daripadanya untuk dijadikan makanan, ubat, pakain dan perhiasan. 
2) Merubah Ajaran Animisme dan Dinamisme Kepada Ajaran Islam

Masyarakat Kerinci walaupun telah memeluk agama Islam, tetapi amalan-amalan anisme ${ }^{14}$ dan dinamisme ${ }^{15}$ masih diamalkan dalam amalan kehidupan mereka antaranya ialah: Memuja roh nenek moyang, memuja makhluk-makhluk halus lainya, memuja hewan, makhluk hidup seperti manusia yang mempunyai kesaktian, dan tumbuh- tumbuhan yang dianggap mempunyai kesaktian seperti pohon beringin daun kelapa muda, padi dan tebu. Serta, benda yang tidak bernyawa, seperti api banyak memberi mamfaat, dan air yang dianggap dapat menhilangkan kotoran jasmani dan rohani.

Sebelum h. Mukhtar menyebarkan dakwah Islamiah, amalan diatas masih berlaku ditengah-tengah masyarakat Kerinci, terutama daerah-derah pingiran dan pendalaman yang sukar dilalui atau dihubungi. H. Mukhtar dengan keupayaannya memeberi keyakinan baru kepada masyarakat Kerinci yang berlatar belakang kepercayaan primitive tersebut. Dalam menanggani kepercayaan masyarakat yang masih dipengaruhi oleh animism dan dinamisme, beliau melakukan dua pendekatan, pendekatan pertama berkaitan dengan kepercayaan dan keyakinan, pendekatan kedua melalui peribadatan. Berkaitan dengan pendekatan pertama yang menyangkut masalah kepercayaan dan keyakinan, H. mukhtar hanya meluruskan keyakian itu dengan pengetahuan akidah, dengan menghuraikan siapakah yang patut di imani, dan siapakah yang patut dipuja dan disembah. Sedangkan pendekatan melalui peribadatan yang berbentuk upacara-upacara,

H. Mukhtar turut serta mendengarnya seperti ucapan mantera yang diajarkan atau yang disampaikan oleh sang dukun atau pemangku. Kemudian $\mathrm{H}$. mukhtar membimbing mereka secara baik untuk mengubah bacaan-bacaan dengan ayat-ayat suci Al-Quran atau berbentuk doa. H. Mukhtar melakukan sendiri amalan doa dan bacaan-bacaan yang sesuai dengan Islam untuk berada standing dengan dukun.

Perubahan yang dapat dilakukan oleh H. Mukhtar secara bertahaptahap, dimulai dari keimanan masyarakat tentang adannya Allah SWT disembah yang dipuja dan tempat meminta, melalui peribadatan disesuaikan mengikut cara Islam, seperti puasa (bertapa) untuk mendapatkan daya kekuatan. Di mana ia dilakukan dengan anggapan mendekatkan diri pada Allah SWT. Qurban (sembelih) binatang yang pada asalnya untuk diberikan kepada air, pokok-pokok kayu yang besar, kemudian diubah oleh $\mathrm{H}$. Mukhtar dengan

${ }^{14}$ Animism barasal dari bahasa lathin iaitu anima yang artinya nyawa. Sedangkan isme adalah kata tambahan, memberi arti faham. Jadi animism adalah faham yang mengatakan bahwa segala benda itu bernyawa.Ahmad Afandi, "Kepercayaan AnimismeDinamisme Serta Adaptasi Kebudyaan Hindu-Budha Dengan Kebudayaan Asli Di Pulau Lombok-NTB," Jurnal Historis 1, no. 1 (2016): 2.

15 Dinamisme ertinya suatu faham atau kepercayaan terhadap suatu daya kekuatan atau kekuasaan yang keramat dan tidak berperibadi atau tidak bernnyawa, yang dianggap halus, berjasad serta dapat dimiliki oleh manusia, hewan atau benda. Ibid., 3 . 
melakukan kurban untuk mensyukuri nikmat Allah dan daging tersebut diberikan kepad fakir miskin serta anak yatim. Dengan menempuh tahap-tahap di atas, lambat laun usaha

H. Mukhtar yang gigih dalam menempuh rintangan-rintangan amalan-amalan masyarakat yang sesat akhirnya dapat diterima oleh masyarakat.

\section{b) Matlamat atau Sasaran Dakwah H. Mukhtar}

Sasaran dakwah H. Mukhtar adalah masyarakat Kerinci dan masyarakat sekitarnya untuk menegakan (amar) Ma'ruf dan menegah (nahi) mungkar. H. Mukhtar sudah mengenali sasaran dakwahnya yang terdiri daripada masyarakat majmuk dan berbagai golongan yang mempunyai kerenahnya. Ada yang betul-betul mahu menerima seruan dakwah, ada yang hanya sekedar berminat dan tidak kurang juga yang bersikap acuh tak acuh serta benci kepada ajaran Islam. Masing-masing golongan tersebut telah ditembusi oleh H. Mukhtar menerus pendekatan dakwah islamiah yang mampu mengubah budaya hidup daripada kehidupan jahiliah kepada amalan Islam. diantaranya:

1) Masyarakat Awam

Menurut Mahmuddin masyarakat awam yang menjadi sasaran dakwah H. Mukhtar adalah masyarakat yang pengetahuan agamanya masih rendah dan dangkal walaupun di dalam hal lain mereka terdiri daripada golongan petani, pekebun, peniaga, nelayan dan yang terlibat dalam pertukangan. ${ }^{16}$ Dalam menyampaikan dakwah Islamiah beliau terlebih dahulu cuba mengenali orang yang akan di dakwah, terutama latar belakang masyarakat dari segi pendidikan, amalan social, pengaruh adat, keadaan politik, sumber-sumber ekonomi dan pemikiran atau mentality masyarakat. Seperti hal nya menegnai sasaran dakwah nya dan membedakan metode dakwah nya antara masyarakat kelompok Pentani, Nelayan dan para pekerja lainnya.

Dakwah H. Mukhtar lebih menekankan kepada menjauhi perbuatan dusta (bohong atau menipu), mengerti hokum menjual beli, selok belok hukum riba, pesanan barang, huatng piutang, gadaian atau sewa menyewa. H. mukhtar menganjurkan kepada pedagang dalam usaha perdagangannya berniat menolong orang-orang Islam berusaha untuk memperolehi segala sesuatu yang mereka usahakan karena mereka juga mendapat pahala. Serta, tidak bosan menasihatkan para pedagang untuk bertindak adil, dengan maksud, menjauhi dan meninggalkan penganiayaan, penipuan, menyebunyikan kecacatan, mengurangi tukaran dan timbangan serta semua hal yang diharamkan. Beliau mendorong agar menjadi pedagang yang baik. Antara amal baik yang semestinya dilakukan oleh para pedagang

${ }^{16}$ Mahmuddin, "strategi dakwah terhadap masyarakat agraris," Jurnal Dakwah Tabligh 14, no. 1 (2013): 101-13. 
ialah mahu menjual secara murah tapi tidak merugikan diri, mudah dalam waktu membeli dan berlapang dada waktu memberi hutang dan waktu meminta kembali hutangnya.

2) Generasi Muda

Menurut H. Mukhtar, kemunculan generasi muda mempunyai kaitan erat dengan perubahan social, iaitu perubahan struktur dan nilai-nilai social. Generasi mudalah yang memang terlibat langsung di dalamnya, baik sebagai objek mahupun sebagai subjek, terutama mereka yang terpelajar. Generasi yang lebih peka dan lebih capat rasa kerinduaan dan bahkan usaha untuk mengadakan perubahan terhadap harapan social yang diperuntukan kepadanya. ${ }^{17}$ Sasaran ini dinilai tepat, karena dikalangan generasi muda mempunyai pemikiran dan pemandangan baru dari peranan yang dimainkan, baik dalam bidang ekonomi, social, kebudayaan dan politik serta usaha dan tindakan dalam menemukan identity diri telah merumuskan kewujudannya sebagai warga masyarakat. ${ }^{18}$

Dalam konteks ini, $\mathrm{Hj}$, Mukhtar ingin membentuk generasi muda muslim yang berakhlak, berani dan bertanggung jawab sebagaimana yang diterapkan dalam generasi muda di bawah naungan al-Maududi dan Hasan al-Banna iaitu untuk saling kenal.

mengenal antara satu dengan lain bagi mewujudkan visi dakwah Islamiyah di Kabupaten Kerinci. Pengaruh dari dua orang tokoh diatas, cukup mempengaruhi corak dakwah Hj. Mukhtar kepada generasi muda, apalagi dengan pemikiran Rasyid Ridha dan Muhammad Abduh. Tetapi di Kerinci menurut wali Ahmad bekas pengetua Depertemen Agama Kerinci ( 1997 ) bahawa Hj. Mukhtar menyatukan pemuda - pemuda Kerinci dalam satu Kesatuan di bawah Jamiat Jihadiyah. Di dalam jamiat inilah programprogram dakwah disampaikan tanpa mengira sama ada apakah mereka terpelajar ataupun tidak, yang penting pemuda-pemuda Kerinci mempunyai cita-cita besar untuk menegakkan ajaran Islam. Dari sini dapat diketahui, bahawaa dakwah H. Mukhtar kepada generasi muda, adalah dengan cara menanamkan kesadaran kafahaman agama, keperibadian dan budi pekerti luhur serta mempunyai minda dan wawasan yang maju, dengan demikian $\mathrm{H}$. Mukhtar menyediakan fasilitas dan sarana sebagai wadah pembinaan generasi muda Kabupaten Kerinci iaitu masjid dan rumah beliau.

\footnotetext{
${ }_{17}^{17}$ Jauhari and Dkk, Tinjauan Sejarah Kebudayaan Islam Di Alam Kerinci.

18 Muhammad Sufyan Abdurrahman, "Generasi Muda , Agama Islam , Dan Media Baru: Perilaku Keagamaan Gerakan Shift Pemuda Hijrah Bandung," Jurnal Anida:Aktualisasi Nuansa Imu Dakwab) 20, no. 1 (2020): 46-63.
} 
3) Golongan Pembesar

Golonngan pembesar yang menjadi sasaran dakwah H. Mukhatr, tidak hanya pembesar yang ada di Kabupaten Kerinci, seperti, ketua kampong, penghulu, camat dan bupati tetapi dakwahnya sampai kepada gabernor dan menteri. Tujuan H. Mukhtar adalah menginginkan para pembesar dari peringkat kampong hingga peringkat menteri dapat menunaikan amanah yang diberikan masyarakat kepada mereka. Oleh itu mereka hendaklah benar-benar mengabdikan dirinya sebaik mungkin bagi masyarakat Islam. Menurut H. Mukhtar pemimpin yang baik, adalah mereka yang memiliki kriteria-kriateria tersendiri. Kriteria seoarang pemimpin ialah semua perbuatan dan ucapanya dapat diikuti dan ditiru serta mempunyai misi menegakkan kebenaran, selalu memberi bimbingan, melaksanakan keadilan dan selalu bertindak jujur tanpa mengikuti dorongan nafsu amarah.

H. Mukhtar memandang serius tentang pembesar dan pemimpin karena mereka boleh membantu masayarakat dalam pelbagai hal seperti pembangunan mental, spiritual, social, politik serta budaya, dengan melihat perubahan dan kemajuan kyang semakin pesat. Pemimpin dan pembesar jugalah yang boleh diharap untuk melakukan penapisan terhadap permasalahan masyarakat seperti gejala-gejala social yang bukan hanya terjadi di tengah-tengah masyarakat awam tetapi juga terjadi pada masyarakat intelek.

\section{c) Halangan Dakwah Syekh H. Mukhtar}

Walaupun dakwah Islamiyah yang dilaksanakan oleh H. Mukhtar berkembang dengan pesat di Kabupaten Kerinci, namun kepesatan dakwahnya juga mendapat halangan dari berbagai masyarakat atau kampong yang masih mengamalkan tradisi lama.

1) Masyarakat Yang Jahil Tentang Agama

Sekalipun masyarakat Kerinci telah menerima dan mengakui bahwa Islam adalah agama penghayatan tulin, tetapi secara tidak sedar, mereka masih melakukan amalan- amalan jahaliyah. Ini disebabkan mereka tidak mengenal konsep dan ciri jahiliyah itu sendiri, baik melalui kitab suci Al-Quran dan al-Hadith ataupun menerusi berita sejarah silam dan bentuk kejahilan yang berkembang ditengah-tengah masyarakat Kerinci. Kejahilan yang berupa kepercayaan ialah mempercayai Thagut, mempercayai kesialan tanda-tanda yang dibawa oleh burung-burung tertentu, mempercayai tukang-tukang tenung, nujum dan ramal. Kejahilan yang berbentuk amalan ialah penyembelihan hewan dikawasan kubur, mengadakan perayaan di perkuburan, mengadakan kenduri tolak bala dan memuja semangat padi. 


\section{2) Ajaran Kebatinan}

Di Kerinci ada dua bentuk kebatinan yang telah tumbuh dengan subur sebelum dan semasa pengembangan dakwah Islamiah yang dilakukan oleh H. Mukhtar. Mereka terdiri daripada golongan yang hendak mengunakan kekuatan-kekuatan ghaib untuk melayani pelbagai keperluan dan golongan yang berusaha untuk mempersatukan jiwa manusia dengan Tuhan. Ajaran golongan yang pertama lebih mengarahkan kepada ilmu ghaib yang menjurus kepada ajaran sesat, manakala golongan kedua lebih menjurus kepada aliran Thariqat. Penganut ajaran kebatinan di Kerinci lebih percaya kepada ucapanucapan orang kuno daripada Al-Quran itu sendiri. Mereka sangat marah bila dikatakan bukan orang Islam. Amalan-amalan yang mereka lakukan telah membelakangkan ajaran Islam yang terkandung di dalam Al-Quran dan hadith Rasul dan mereka telah menyalahgunakan ayatayat Al-Quran itu sendiri dalam praktik kebathinan.

\section{3) Kepemerintahan}

Negara Republik Indonesia yang mencapai kemerdekaan pada 17 Agustus 1945 yang berfalsafahkan pancasila dan UUD 45 (UndangUndang Dasar 1945) maka segala bentuk dan corak ideology yang ada semestinya berdasarkan kepada dua asas tersebut. Sedangkan $\mathrm{Hj}$. Mukhtar yang telah melahirkan satu organisasi besar di Kerinci yaitu Jamiatul Ihsaniah mempunyai filsafat yang lain iaitu untuk menciptakan dan melahirkan satu masyarakat islam yang berdasarkan kepada alQuran dan Sunnah Rasullah saw.

Keperintahan menjadi halangan dalam perjalanan dakwah H.Mukhtar karena pada masa orde lama beliau pernah dicekal. Walaupun digantung kegiatan dakwahnya, namun murid-murid beliau tetap aktif. Melihat kenyataan seperti itu, beliau tidak mendaftarkan organisasinya dalam pengelolaan pemerintah Indonesia, tetapi organisasi yang berdiri sendiri. Oleh itu segala aktiviti-aktiviti dakwahnya tidak pernah menerima bantuan atau sumbangan dari pemerintah.

\section{Penutup}

Syekh H. Mukhtar Abdul Karim dalam menjalankan aktiviti dakwahnya, telah menyusun beberapa perancangan yang akan dilaksanakan. Antaranya ialah menyeru masyarakat kepada kebenaran, merubah ajaran animism dan dinamisme. Perkara diatas dipandang serius oleh beliau, kerana masyarakat Kerinci ketika itu masih dilatar belakangi oleh pengaruh agama primitive, kemungkaran, kejahilan dan kezaliman. Oleh itu beliau mengarahkan sasaran dakwahnya kepada masyarakat awam, generasi muda dan golongan pembesar. Beliau menjadikan kegiatan dakwah 
islamiahnya sebagai system dalam perjalanan peradaban yang berfungsi untuk mencapai kebaikan dalam seluruh kehidupan, menjadikan kebenaran sebagai pelita hidup, mengarahkan pencapaian kemajuan untuk tujuan-tujuan yang baik, membanteras kejahilan dan memperhebatkan hubungan antara manusia dengan sang pencipta Allah SW'T dan sesama makhluk.

\section{Daftar Pustaka}

Abdurrahman, Muhammad Sufyan. "Generasi Muda , Agama Islam , Dan Media Baru: Perilaku Keagamaan Gerakan Shift Pemuda Hijrah Bandung." Jurnal Anida:Aktualisasi Nuansa Ilmu Dakwah) 20, no. 1 (2020): 46-63.

Afandi, Ahmad. "Kepercayaan Animisme-Dinamisme Serta Adaptasi Kebudyaan Hindu- Budha Dengan Kebudayaan Asli Di Pulau Lombok-NTB." Jurnal Historis 1, no. 1 (2016): 1-9.

Akhirudin. "DAKWAH DAN PEMBAHARUAN PEMAHAMAN ISLAM." KORDINAT

XVII, no. 2 (2018): 399-418.

Asmuni, Yusran. Pengantar Studi Pemikiran Dan Gerakan Pembaharuan Dalam Dunia Islam. Cet-2. Jakarta: Raja Grafindo Persada, 1998.

Beek, H.L., and N.J.G Kaptien. Pandangan Barat Terhadap Literatun Hukum, Filosofot, Teologi Dan Mistik Tradisi Islam. Jakarta: INIS, 1998.

Choliq, Abdul. "Dakwah Melalui Media Sosial Facebook." Jurnal Dakwah Tabligh Vol.16, no. 2 (2018): 170-87.

Creswell, Jhon. W. Research Design: Pendekatan Kualitatif, Kuantitatif Dan Mixed. Yogyakarta: Pustaka Pelajar, 2010.

Ismail A, Ilyas. Filsafat Dakwah, Rekayasa Membangun Agama Dan Peradaban Islam. Jakarta: Kencana, 2011.

Jauhari, Budhi Vrihaspati, and Dkk. Tinjauan Sejarah Kebudayaan Islam Di Alam Kerinci.

Sungai Penuh: Bina Potensia, 2014.

mahmuddin. "STRATEGI DAKWAH TERHADAP MASYARAKAT AGRARIS." Jurnal

Dakwah Tabligh 14, no. 1 (2013): 101-13.

Nasution, Harun. Pembaharuan Dalam Islam Syarah Pemikiran Dan Gerakan. cet-8, 1991. 
P.S.J. Van Koningsvela. Naskah-Naskah Yunani Tentang Bait Al-Hikmah Dan Kebijakan Khalifah Al-Ma'mun Dalam Herman Leonard Beek Dan Niro Kaptien (Red) Studi Belanda Kontemporer Tetang Islam. Jakarta: INIS, 1993.

Rifyal Ka'bah. "Modernisme Dan Fundamentalisme Ditinjau Dari Konteks Islam.” Jurnal Ilmu Dan Kebudayaan Ulumul Qur'an 3, no. VI (1998).

Sa'Id, Bustami Muhammad. Gerakan Pmebaharuan Antara Agama MOdernisme Dan Tajdiduddin. Bekasi: WacanaLazuardi, 1995.

Saleh, Indriany Aisyah, Chatib Saefullah, and Tata Sukayat. "Problematika Dakwah Penyuluh Agama." Tabligh Jurnal Komunikasi Dan Penyiaran Islam 5, no. 3 (2020): 287-308.

Sjamsudin, H. Metodologi Sejarah. Yogyakarta: Ombak, 2012.

Sugiyono. Metode Penelitian Kuantitatif, Kualitatif Dan R\&D. Cet ke-26. Bandung: Alfabeta, 2017 